\title{
2006-156: EXPERIMENTAL RESEARCH IN THE DAYLIGHTING SYSTEMS ENGINEERING
}

\section{Khaled Mansy, Oklahoma State University}

Khaled A. Mansy is an Assistant Professor in the Architectural Engineering Program, School of Architecture, Oklahoma State University. He earned his Ph.D. from Illinois Institute of Technology, Chicago, 2001, and has 16 years of teaching experience in professional programs in the USA and Egypt. Dr. Mansy is the PI of the NSF grant awarded to build this daylighting laboratory; the artificial sky dome.

\section{Steven O'Hara, Oklahoma State University}

Steven O'Hara is a Professor of Architectural Engineering, School of Architecture, Oklahoma State University. He received his Bachelor of Architectural Studies and Master of Architectural Engineering from Oklahoma State University, 1982 and 1985 respectively. Professor O'Hara is also a registered Professional Engineer. He has been teaching structural design since 1988. 


\title{
Experimental Research in the Daylighting Systems Engineering
}

\begin{abstract}
In the midst of the current environment-conscious era, sustainable architecture and sustainable engineering are seen as the vehicle to creating green buildings. This paper investigates the role of daylighting systems in green design. The paper argues that: engineering of daylighting systems is necessary to optimize the use of energy in buildings. The use of engineering principles in the design for daylight may overcome the current barriers to effective incorporation of daylighting systems in buildings; in academia and in practice. That is why more emphasis should be given to experimental research in the field of daylighting systems in order to establish a set of rigorous engineering principles for the design of daylighting systems. In the end, the paper gives a brief description of a new model of an artificial sky dome that is designed by OSU faculty. This artificial sky dome is now under construction and will be used by undergraduate and graduate students to perform experimental research in the field of daylighting design.
\end{abstract}

\section{Introduction: Dilemma of Green Design}

Green design, also known as sustainable design, is a relatively new field of expertise. According to a recent definition of sustainable architecture, sustainable buildings should be both ultraefficient (also known as high-performance) and environment-friendly ${ }^{1}$. Being ultra-efficient is to maintain a desirable quality of life with minimal use of natural resources, i.e., energy, water and materials. Being environment-friendly is to assure that buildings, in their construction, operation, and demolition do not disturb the balance of ecosystems nor pollute or exhaust natural resources. Indeed, green (or sustainable) architecture is not a new architectural style. It is rather a new generation of buildings that perform more efficiently and do not harm the environment. Both ultra-efficiency and environment friendliness are achievable through rigorous engineering of building systems. That is why engineering of building systems, including daylighting systems, should be considered an underlying principle of sustainable architecture. That is where rigorous architectural engineering of green buildings becomes an inescapable task in green design.

Historically speaking, in the post-industrial revolution era, separation between architectural design and engineering of buildings contributed to the fragmentation of the design process. Because modern technology was developed in a relatively short period of time and was complex, the practice of architecture had to be organizationally divided into different sub-disciplines. This is primarily why it became almost impossible for architects to be sufficiently knowledgeable to make conceptual design decisions regarding the technical aspects of modern buildings, i.e., environmental and structural systems ${ }^{2}$. It is unfortunate that the current professional practice, in general, is still following the same post-industrial revolution fragmented paradigm of design.

In the $21^{\text {st }}$ Century, in the environment-conscious era, green design of buildings should follow a new holistic paradigm of design. Because sustainability is a holistic approach, full integration between the design of a building and the design of its systems (active and passive) is essential. In an integrated design process, all members on the design team, i.e., architects and architectural engineers, should collaborate during all design phases. Design and coordination of building systems, including daylighting systems, should start in the beginning of the design process. Only 
through early design collaboration and coordination, sustainable architecture can be achievable. While early engineering of building systems can affect how sustainable a building is in so many ways, this paper will only address the role of early engineering of daylighting systems and how this should impact the education of the next generations of architectural engineers. The information presented in this paper is used in teaching daylighting systems to undergraduate students in an elective course offered in the School of Architecture, Oklahoma State University.

\section{Electric Lighting in Buildings}

According to the Energy Information Administration, an average of 51.4\% of the site electricity consumption in major commercial buildings in the US is consumed by electric lighting systems. That is 59\% in retail and service buildings, 56\% in education buildings, $44 \%$ in office buildings, $44 \%$ in health care buildings, and $30 \%$ in food service buildings [refer to Figure 1]. When other forms of site energy sources are considered, e.g., natural gas and fuel oil, electric lighting systems found to consume an average of $\mathbf{2 6 . 2 \%}$ of the site energy consumption. That is $31 \%$ in retail and service buildings, $29 \%$ in office buildings, $20 \%$ in education buildings, $16 \%$ in health care buildings, and $15 \%$ in food service buildings ${ }^{3}$. Actual US consumption values are shown in table 1 . However, it is worth-mentioning here that these numbers are location-dependant, and lighting energy may account for higher than the national average, especially in temperate climates. In the State of California, electric lighting systems consume 39\% of total site energy of commercial buildings, which is a much higher percentage than the national average [refer to Figure 2] $]^{4}$. In Canada, where there is a significantly higher demand for heating, electric lighting systems consume only $\mathbf{1 3 \%}$ of total site energy of commercial buildings, which is almost half the US average [refer to Figure 3$]^{5}$.

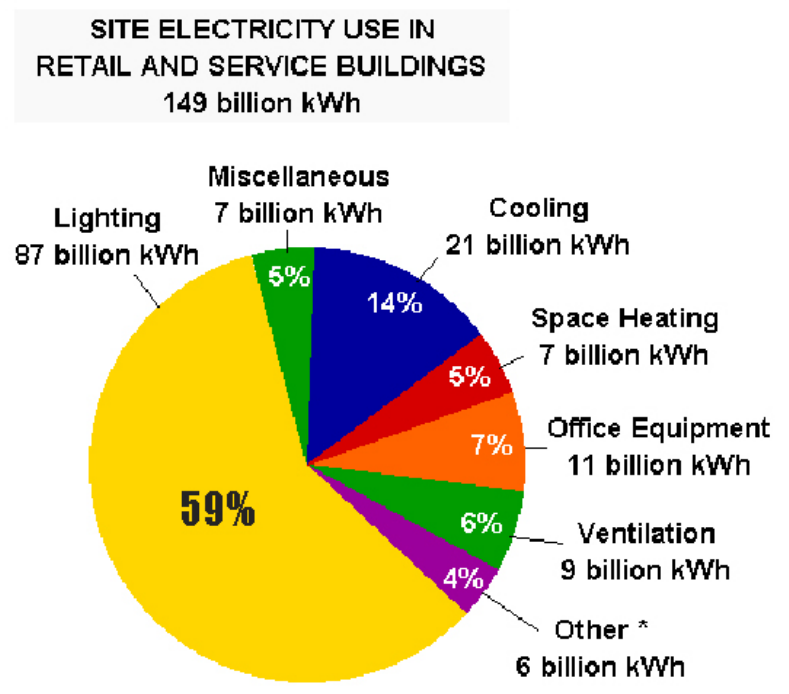

* Other includes refrigeration ( 3 billion $\mathrm{KWh}$ ), water heating (2 billion $\mathrm{kWh}$ ), and cooking (1 billian kWh).

Note: Due to rounding, individual figures may not sum to totals.

Source: Energy Information Administration, 1995 Commercial Buildings Energy Consumption Survey.

Figure 1a: Site electricity split in retail and service buildings in the US, 1995.
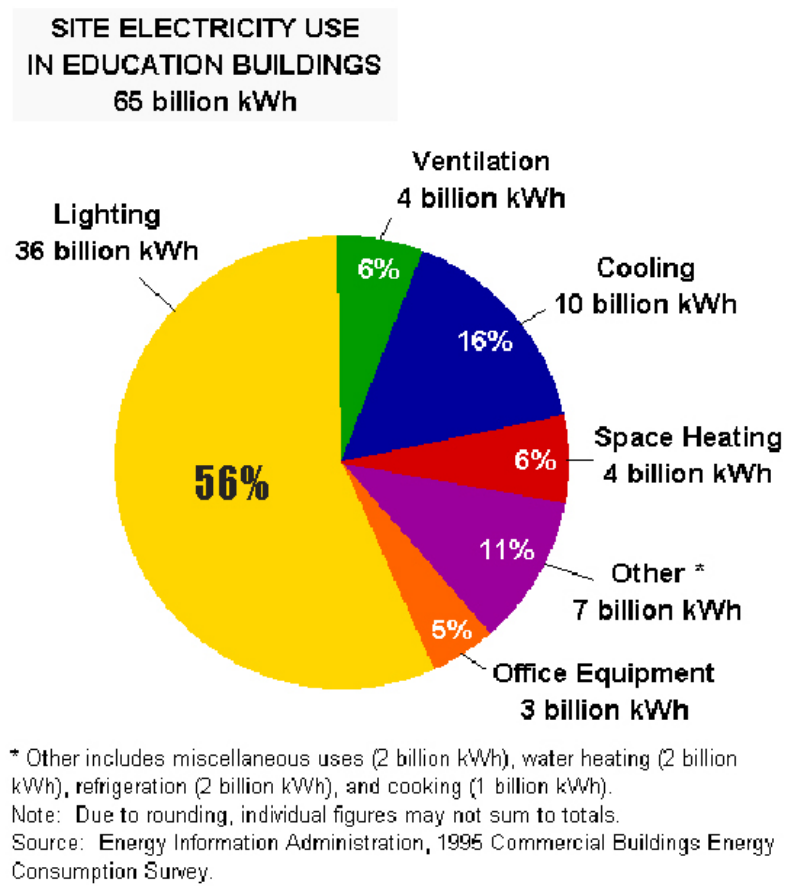

Figure 1b: Site electricity split in education buildings in the US, 1995. 

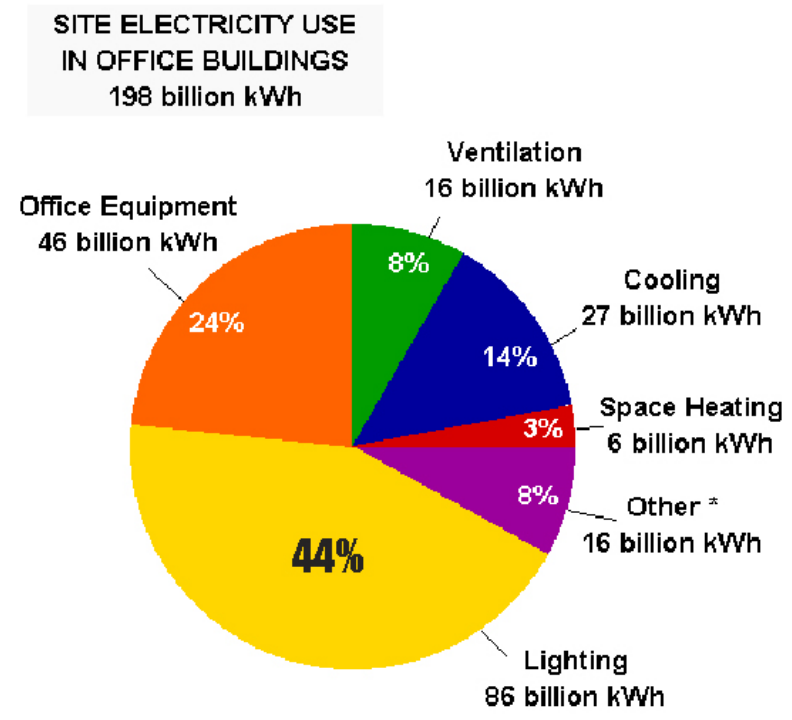

* Other includes miscellaneous uses (13 billion KWh), water heating (2 billion $k W h$ ), refrigeration (1 billion $k W h$ ), and cooking ( $<1$ billion $k W h$ ).

Note: Due to rounding, individual figures may not sum to totals.

Source: Energy Information Administration, 1995 commercial Buildings Energy Consumption Survey

Figure 1c: Site electricity split in office buildings in the US, 1995.
SITE ELECTRICITY USE

IN HEALTH CARE BUILDINGS

62 billion $\mathrm{kWh}$

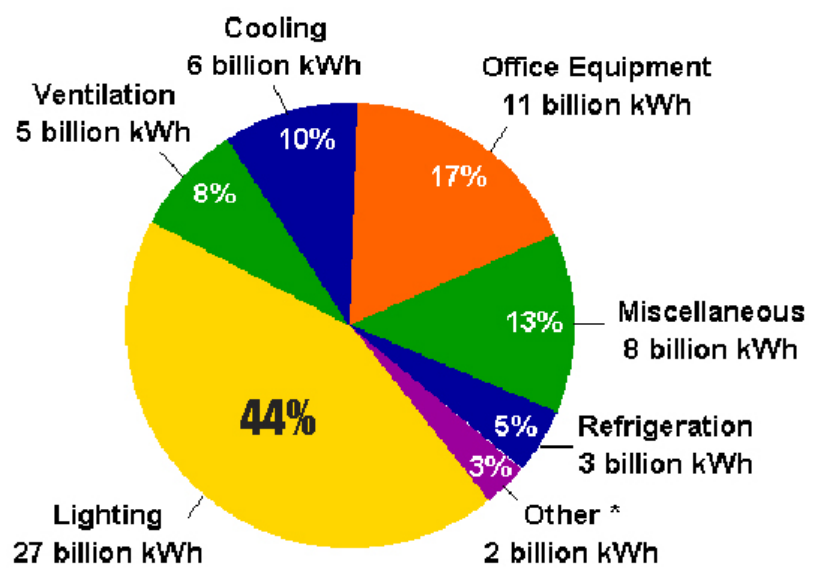

* Other includes space heating ( 1 billion kWh), water heating ( 1 billion kWh). and cooking ( $<1$ billion $\mathrm{kWh}$ )

Source: Energy Information Administration, 1995 Commercial Buildings Energy Consumption Survey.

Figure 1d: Site electricity split in health care buildings in the US, 1995.

Table 1: Annual site energy consumption in commercial buildings in the US (1995)

\begin{tabular}{|l|c|c|c|c|}
\hline Building Type & $\begin{array}{c}\text { \% of commercial } \\
\text { buildings by area }\end{array}$ & Site Energy* & Site Electricity* & $\begin{array}{c}\text { Electric Lighting } \\
\text { Energy* }\end{array}$ \\
\hline Retail and Service Buildings & $22 \%$ & 973 & 508 & 298 \\
\hline Education Buildings & $13 \%$ & 614 & 221 & 122 \\
\hline Office Buildings & $18 \%$ & 1,019 & 676 & 294 \\
\hline Health Care Buildings & $4 \%$ & 561 & 211 & 92 \\
\hline Food Service Buildings & $3 \%$ & 332 & 166 & 50 \\
\hline
\end{tabular}

* Values are in Trillion Btu.

- Commercial sector accounts for $17 \%$ of the national energy consumption.

- Total site energy consumption in all commercial buildings is 5,321 Trillion Btu.

- The five listed building types represent $60 \%$ of commercial buildings by area, and consume $66 \%$ of commercial sector's energy.

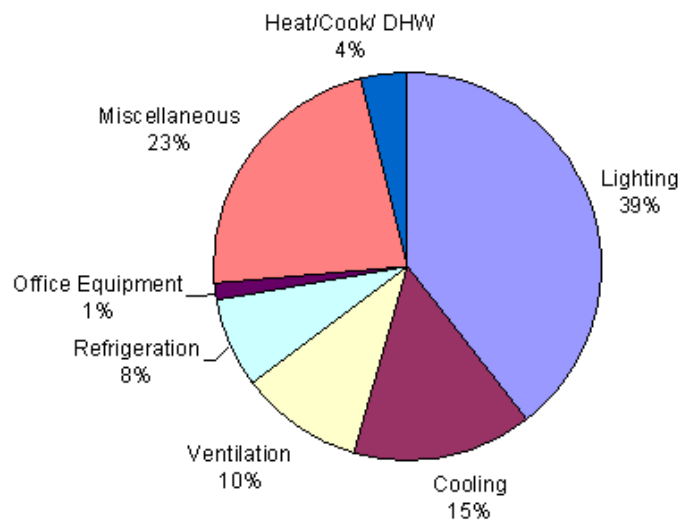

Figure 2: Commercial energy end use split, California energy demand, 2000-2010.

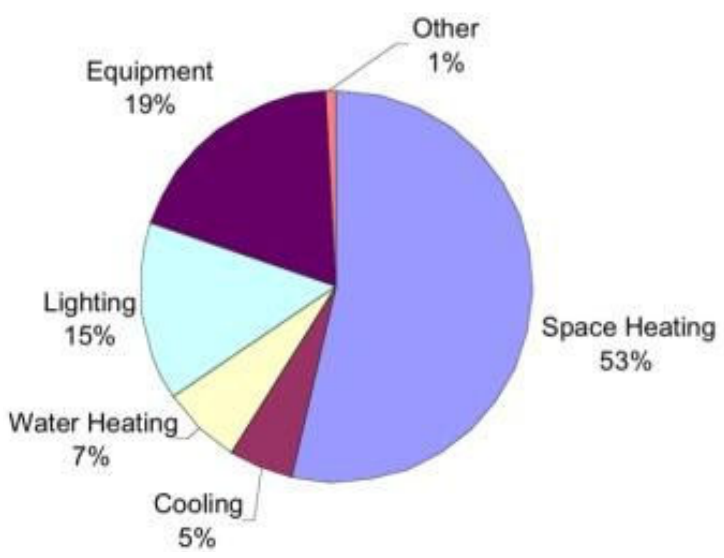

Figure 3: Commercial energy end use split in Canada, 2001. 
In conclusion, in the US, electric lighting systems in buildings consume a significant percentage of electricity. A potential green design strategy to save energy in commercial buildings would be the integration between daylighting systems and electric lighting systems. However, like other energy-conscious passive design strategies, engineering of daylighting systems is being grossly overlooked in all design phases; in both academia and professional practice. It is a huge saving opportunity that should be revisited.

\section{Daylighting Systems as Engineered Passive Building Systems}

Engineering of daylighting systems is a necessity for a successful green design. Rigorouslydesigned and engineered daylighting systems, if associated with an appropriate electric lighting control, can save a significant amount of energy is currently being consumed in commercial buildings. This can only be possible if the engineering of lighting systems in buildings considers daylighting systems as the primary source of light, and then design electric lighting systems as supplementary systems. In other words, design of electric lighting systems should not anymore be limited to the worst case scenario in which the building operates during night when daylight is unavailable. Integration between daylighting and electric lighting systems is a must. It should be the norm in sustainable engineering, in academia and in professional practice.

Engineering of mixed-mode (passive/active) building systems is a new challenge in the ecotechnology era. Design of passive systems is a delicate and complex task. Dual control of passive and active systems is another. This section of the paper, section 3, addresses the design of daylighting systems as passive systems; their advantages and disadvantages (compared to electric lighting systems); and the challenges facing their design. It is worth-mentioning here that daylighting is also considered a bioclimatic strategy, whereas bioclimatic design is defined as the utilization of naturally-occurring flows of energy to provide human comfort.

\subsection{Advantages of Daylighting Systems}

Advantages of daylighting systems include the following:

a. Daylighting systems reduce lighting energy use. Daylight is a free renewable source of light that is available almost everywhere on the planet.

b. Daylighting systems reduce space cooling load. Both sunlight and daylight (sky component) are of a higher efficacy than artificial light sources ${ }^{6}$. Cooling load reduction helps creating ultra-efficient buildings.

c. Daylight is an environment-friendly source of energy. Daylight is a naturally-occurring flow of energy that does not require building power plants or transmission grids.

d. Daylight has the best light quality, compared to artificial light sources. Daylight has a rendition index of 1.0, which is the index of light quality.

e. Daylight is most available during peak demand hours; around noon time. Utility companies apply a demand charge to electricity consumed during peak hours, which maximizes the cost effectiveness of the integration of daylighting systems, i.e., reduces the payback period of the cost of daylighting systems.

f. Daylighting systems encourage the visual integration between inside and outside. Daylight is introduced to spaces through windows and skylights that provide view to outside as well. 
g. Daylight improves human productivity. Recent studies confirmed that students learn faster in daylit classrooms, better worker performance in daylit work environment, and increased retail sales under skylights ${ }^{7}$.

\subsection{Disadvantages of Daylighting Systems}

Disadvantages of daylighting systems include the following:

a. Continuous intensity fluctuation over time: Outdoor illumination levels are timedependant. They change from season to season and from hour to hour depending on solar intensity and sun's position in the sky.

b. High uncertainty due to unpredicted climatic conditions: Outdoor illumination level is highly affected by the cloud cover, which can not be accurately predicted.

c. Non-uniform distribution of illumination level in case of side-lighting systems: In the common side-lighting systems (windows), illumination levels close to the exterior are much higher than deep in the space [refer to Figure 4].

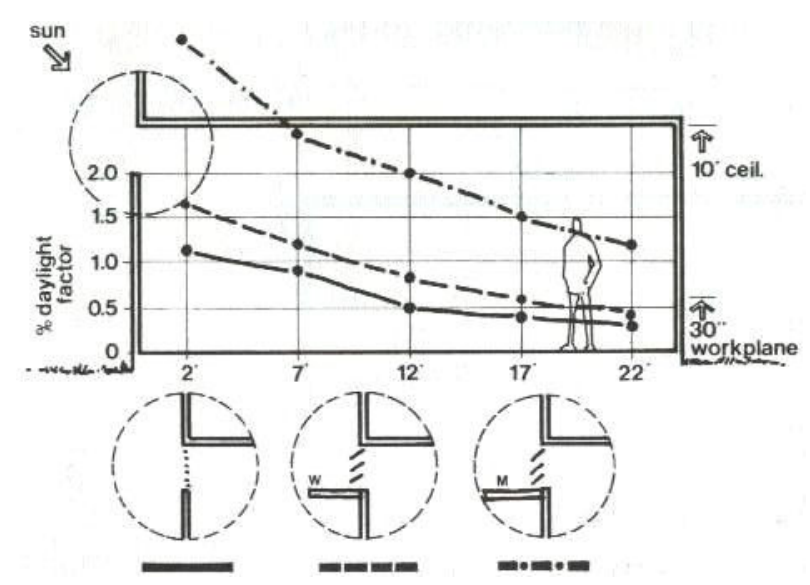

\subsection{Design Challenges Facing Daylighting Systems}

In addition to the afore-mentioned disadvantages of daylighting systems, the nature of daylight and sunlight exhibit real challenges to the design and/or engineering of daylighting systems. Four design challenges can be summed as follows:

a. Establish design conditions for daylighting systems. In order to design and/or engineer daylighting systems, a set of design conditions should be defined. Currently, there is an agreement that overcast sky condition is the worst case scenario ${ }^{8}$. However, there is no agreement on time-dependant design conditions. Possible time-dependant design conditions can be ${ }^{9}$ :

- Design for minimum acceptable natural illumination under minimum available daylight conditions, such as, 9:00 a.m. in December, whereas the system's design should screen out excess illumination at all other times.

- Design the system to provide adequate light under average sky conditions. Hence, supplementary lighting is necessary when less-than-average daylight is available, and screening out excess illumination is desirable when more-than-average daylight is available. 
- Design for adequate natural illumination during the majority of typical working hours.

b. How to size and control the aperture in order to provide the minimal amount of daylight. The design of daylighting systems should avoid oversizing aperture that may unnecessarily increase solar load and cooling load in the space. With higher than necessary solar load the building loses its efficiency and becomes less environmentfriendly (even compared to electric lighting), i.e., less green.

c. How to provide a uniform distribution of illumination level via the utilization of daylight. Uniform distribution of illumination level is achievable by toplighting systems, and by double-expose (north \& south) sidelighting systems. However, in single sidelighting systems, achieving uniform distribution is a challenge.

d. How to control the electric lighting system in order to use minimal amount of electricity. A responsive electric lighting system, controlled by photoelectric sensors, is a necessity. Such high-tech control is currently expensive.

The afore-mentioned design challenges are also barriers to the incorporation of daylighting systems in buildings. Further research and development are needed to overcome these barriers; before daylight utilization becomes the norm in building design, in academia and in professional practice.

\section{Current Status of Daylighting Systems' Design in Academia \& Practice}

Currently, the design of daylighting systems is grossly overlooked by both architects and architectural engineers. During the design process, neither architects nor engineers pay enough attention to the design of daylighting systems. No scientific prediction of the performance of daylighting systems takes place. The majority of the commonly-used methods and designassisting tools do not provide a meaningful feedback on the performance of daylighting systems. This is the case in both academia and practice. A solution is needed to advance sustainable design and technology.

In academia, students tend to learn from precedents of successful designs of daylighting systems. When students are asked to rigorously design daylighting systems, they normally utilize rules of thumb, which are suited for the schematic design phase. Quantitative rules of thumb often used in design studios are: the rule of 2.5 , the $15 / 30$ rule, and the one tenth rule ${ }^{10}$. In academia and practice, because of the current inability to evaluate the performance of daylighting systems, they tend to be conceived as a visual phenomenon that relates more to the architectural aesthetics and not to the engineering of buildings ${ }^{11}$.

\section{Design/Engineering of Daylighting Systems}

A rigorous design/engineering procedure is needed to guide the design of daylighting systems in buildings. This procedure should accurately take into account all variables that may affect the performance of daylighting systems. In addition, this procedure has to follow a clear and consistent set of design objectives. This paper suggests the following design objectives, design conditions, and list of variables that should be taken into account during the design of daylighting systems. 


\subsection{Design Objectives}

Three quantitative and qualitative design objectives are suggested below:

a. Sufficient illumination level on the workplane within the perimeter space, for at least the depth of 16 feet from exterior walls, or at least the depth covered by two rows of electric lighting fixtures.

b. Uniform distribution of illumination levels on the workplane as possible. Ratio between highest and lowest illumination levels should not exceed the ratio of 2:1, which is the ratio between the average efficacy of daylight and the average efficacy of full size fluorescent tubes ${ }^{12}$. If the ratio exceeds the ratio of $2: 1$, excessive heat gain will unnecessarily increase the cooling load.

c. Avoid glare by preventing any penetration of direct sunlight into spaces in which a visual task is performed.

\subsection{Design Conditions}

As for the target illumination level to be provided by daylighting systems, the authors suggest the two alternate design conditions listed below. These suggested target illumination levels are based upon personal experience and can be a subject for further discussions.

- In case there is no responsive control system intended to control the aperture size, the daylighting system should be designed to provide an annual hourly average illumination level that is equal to the required illuminance; under average sky conditions.

- In case the design includes a responsive control system for the aperture size, the daylighting system should be designed to provide an average illumination level during winter (season of the lowest available outdoor illuminance) at solar noon that is equal to the required illuminance.

As for sky conditions to be considered as a design condition, the authors suggest the following:

- In locations with annual sunshine less than 50\%, design conditions should be under overcast sky conditions.

- In locations with annual sunshine more than 50\%, design conditions should be under clear sky conditions.

The data on annual sunshine is available through the National Oceanic and Atmospheric Administration (NOAA). Refer to the map in Figure 5 for a graphic representation of annual possible hours of sunshine conditions in the US ${ }^{13}$.

Figure 5: Annual hours of sunshine in the US.

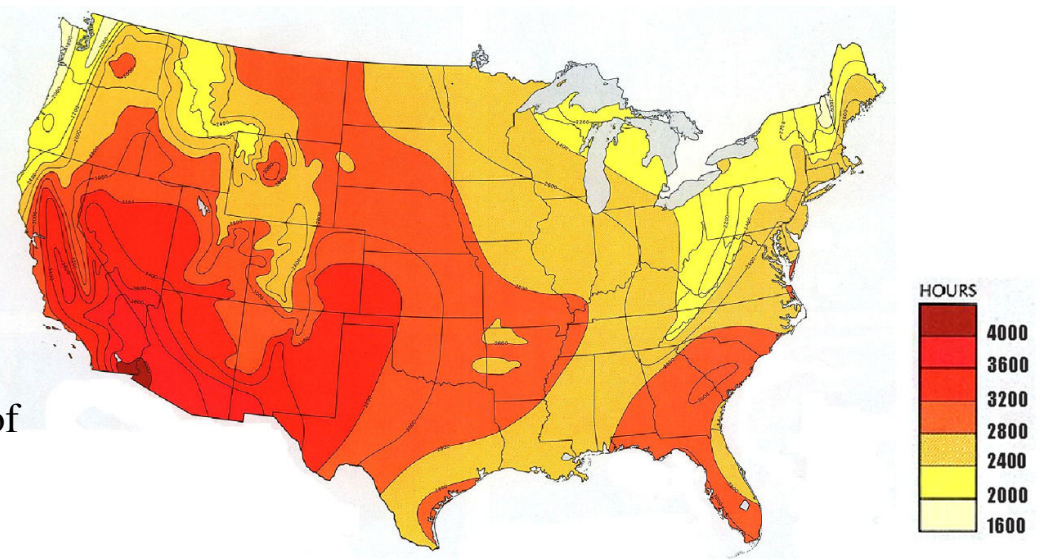




\subsection{List of Design Variables}

To assure a rigorous analysis of the performance of daylighting systems, all variables that may affect their performance should be taken into account. These variables are listed below ${ }^{14}$. These variables relate to the site, design of space, and design of windows.

a. Building location, i.e., apparent sun movement and intensity of sunlight.

b. Sky conditions and their percentage annual occurrence.

c. Ground reflection.

d. Space orientation, i.e., South, North, East, and West.

e. Exterior obstruction, i.e., nearby structures and/or neighboring buildings.

f. Size of openings, i.e., windows and/or skylights.

g. Placement of openings.

h. Detailed design of openings, e.g., overhangs, light shelves, ... etc.

i. Form of the ceiling.

j. Reflectances of interior surfaces.

k. Design of the space, i.e., rectilinear, irregular, ... etc.

1. Type of glass used, i.e., its visible transmittance.

$\mathrm{m}$. Level of maintenance provided for the space.

n. Task performed in the space, i.e., the recommended illumination level.

o. Height of the workplane above the floor, where illumination level is measured.

p. Type of the desired lighting system, i.e., general, task, or a combined general and task.

q. Schedule of occupancy in the space; daily and seasonally.

\section{The Need for Experimental Research}

To overcome the current overlooking of daylighting systems and to make their design the norm, further investigative research is needed. Verification and further development of what is suggested in section 5 (of this paper) may result in the establishment of engineering principles of daylighting professional practice.

In academia, experimental research in the area of daylighting can be an effective approach to initiate the students' interest in the subject. Design, in general, is a trial and error process, and design of daylighting systems in no exception. Evaluation of the performance of daylighting systems by testing physical scale models is commonly seen as the only accurate method, with the exception of computer programs. The use of computer programs does not suit beginning undergraduate students as a learning tool. Physical scale models are recommended for conceptualization and simple evaluation of proposed design solutions. Even if crudely built and measured, scale models are considered a more reliable tool for revealing the quantity, quality, and distribution of light in a space than theoretical mathematical calculations or drawings ${ }^{15}$. A daylighting laboratory facility is necessary to allow students to conduct experimental research.

At the School of Architecture, Oklahoma State University, there is a strong interest in green design. As a means to integrate green design in both architectural engineering and architectural programs, the school is building a state-of-the-art daylighting laboratory, i.e., an artificial sky dome. Students will use the lab to obtain performance data by testing scale physical models under different sky conditions, then, this data will be used to predict the potential energy savings 
due to the integration between daylighting and electric lighting systems. Section 6.1 reports on the design of the laboratory. Section 6.2 gives a brief on the calculation procedure, which has been already published, in detail, in a previous paper.

\subsection{The Artificial Sky Dome Laboratory}

The artificial sky dome laboratory, which is currently under construction, will enable a rigorous quantitative investigation of the design and engineering of daylighting systems in buildings. The lab will be used by both architectural engineering and architecture students during design studios and advanced elective environmental control lecture courses. The design of the lab was discussed in a previous ASEE paper ${ }^{16}$. However, this section highlights the advantages of this lab compared to other labs and methods currently used for the same purpose, i.e., testing physical scale models of daylighting systems. Refer to Figure 6 that shows the design of the lab.

Advantages of the artificial sky dome laboratory can be summed as follows:

- Simulate different sky conditions: the new lab will be capable of simulating an array of different sky conditions, i.e., overcast sky and clear sky conditions. This will allow the students to design the daylighting systems under the established design conditions, then, study the impact of other sky conditions in order to investigate the impact of sun position and potential associated glare. This study cannot be performed using other labs that simulate one sky condition, i.e., overcast sky only or clear sky only.

- Accuracy: because the new lab is constructed as a fixed dome with a heliodon inside, it can accurately simulate clear sky conditions, compared to using a tilting table to perform the same analysis. When using a tilting table outdoor to simulate clear sky conditions, tilting the table affects the relative angle between the horizon and the model (refer to Figure 7), which consequently changes the value of sky component inside the model. Inaccuracy of the readings taken inside the model affects the overall results of the analysis.

- No star effect: according to the design of the new lab, the translucent inner dome diffuses the light generated by the lamps mounted on the outer open-frame dome; while maintaining the same distribution of sky luminance. This diffusion prevents the star effect that is found in other labs that consist of one dome with lamps mounted on it. Experiments have shown that even a large number of point source lights will create a star effect (Figure 8). This star effect causes inaccurate readings by the light sensor inside scale models (Figure 9). When the light sensor is moved inside the scale model, it may see a different number of point source lights, which causes unrealistic jumps in the reading of internal illumination levels.

- User-friendly: the new lab is designed as a whole dome that simulates sky with a heliodon inside that simulates the sun. That is why illuminance readings can be taken inside the model only once at each point. In other labs, when the sky is simulated by a scanning sky simulator (Figure 10) the readings at each point inside the model should be taken multiple times, then values are added manually.

- Not weather-permitting: because the new lab is a controlled luminous environment placed inside a windowless room, the lab can be used any time regardless of actual outdoor conditions. In case of testing models outdoor, wind, rain, continuously-moving sun, and continuously-moving clouds are detrimental factors that prevent any testing. 


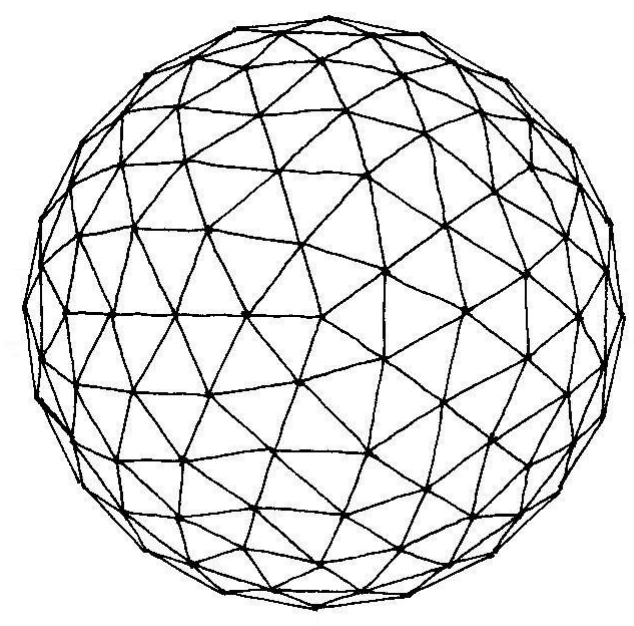

Figure 6 a: Geodesic Dome (plan)

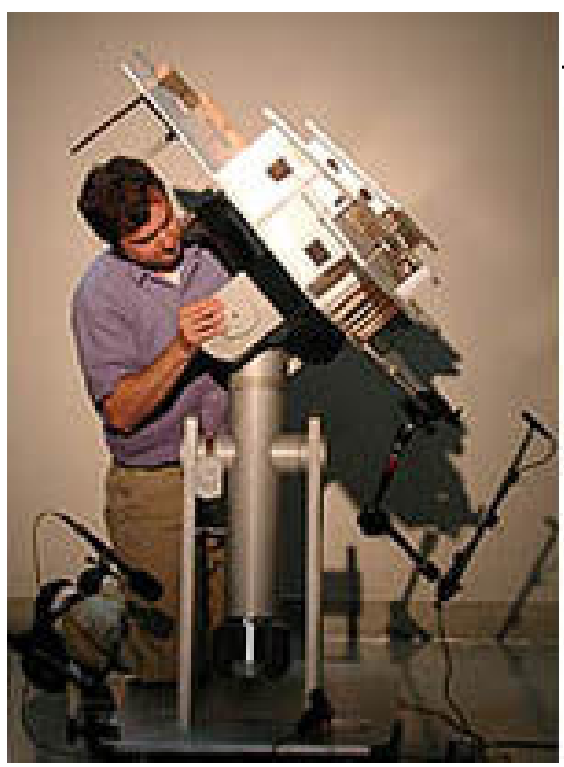

Figure 7: The tilting table heliodon.

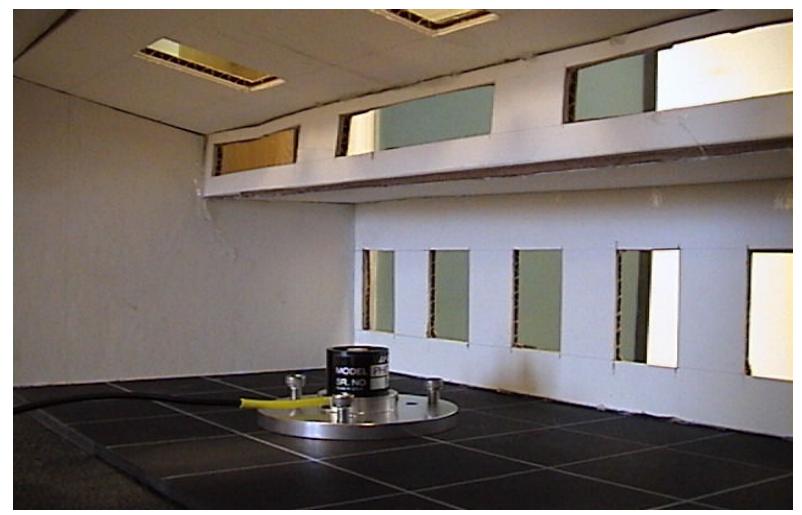

Figure 9: The light sensor inside a scale physical model while measuring internal illuminance.

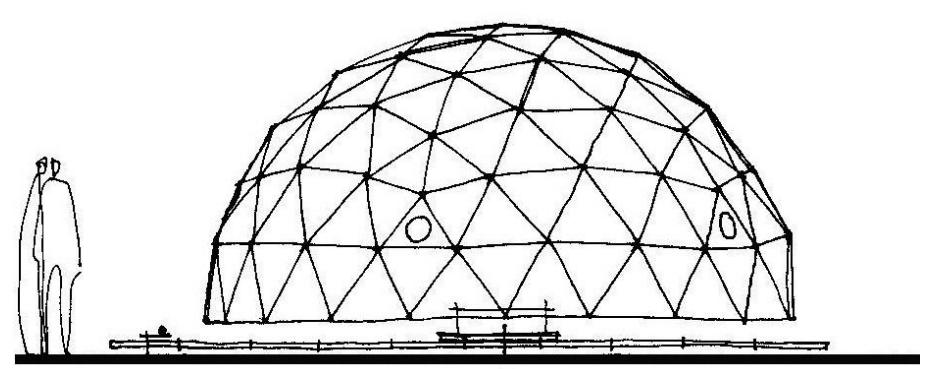

Figure 6 b: Geodesic Dome (elevation)

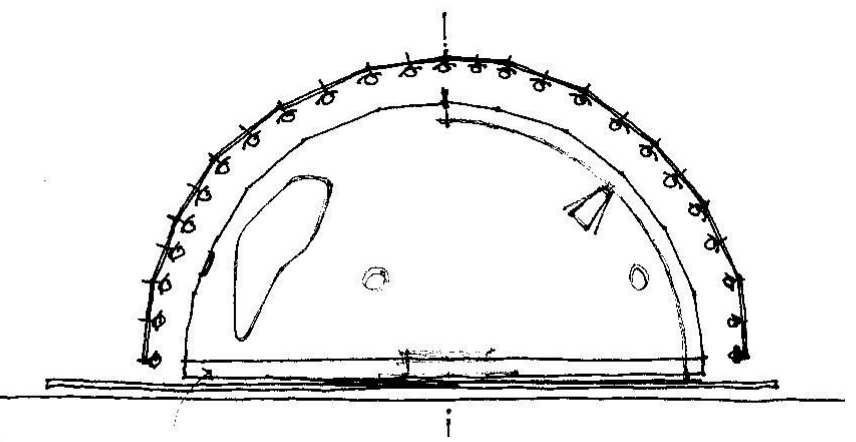

Figure 6 c: Laboratory setup, showing outer and inner concentric domes; and the heliodon.

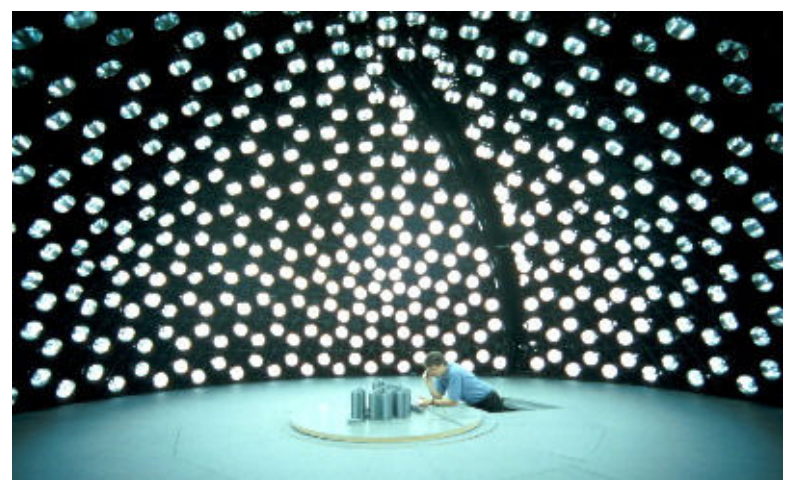

Figure 8: The star effect as seen in the daylighting lab in Cardiff University, UK.

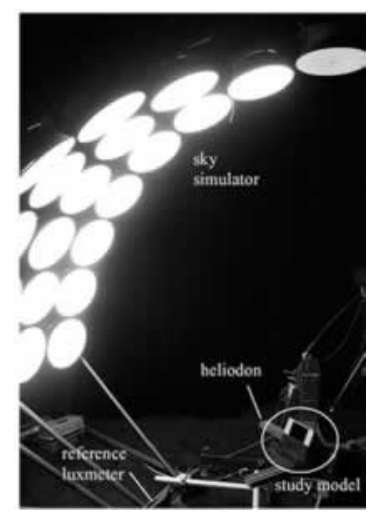

Figure 10: The scanning sky simulator at the Swiss Federal Institute of Technology (EPFL). 


\subsection{Calculation Procedure}

A user-friendly calculation procedure will be used to quantitatively evaluate the performance of daylighting systems based on data obtained from testing the scale physical models under the artificial sky dome. For more details on the calculation procedure, please refer to the article titled: A user-friendly procedure to visualize the hourly quantitative performance of daylighting systems, in the International Solar Energy Journal, volume 77, pp. 373-380. The International Solar Energy Journal (Solar Energy) is accessible online through Science Direct subscription.

\section{Conclusions}

Daylighting systems are a cornerstone in green design. A huge energy saving may be a result of successful integration between daylighting systems and electric lighting systems in buildings. In the current environment-conscious era, a new paradigm of engineering is needed to take advantage of intermittent naturally-occurring flows of energy, e.g., daylight, to provide human comfort inside buildings. Consequently, electric lighting systems should be designed only to supplement (and not to replace) daylight. So far, similar to the current status of the design of passive building systems, the design and engineering of daylighing systems lag behind traditional engineering of active building systems. Complexity of the design of daylighting systems makes it less appealing to architects to undertake and makes it a risky task and liability for architectural engineers. That is why rigorous design and/or engineering of daylighting systems is uncommon in architectural practice. Further experimental research is needed to establish a rigorous design procedure for the design of daylighting systems. In academia, there is a dire need for undergraduate and graduate education and exploration in the area of daylighting systems design and engineering. The new daylighting laboratory, the artificial sky dome, at Oklahoma State University, will provide the means of exploration to perform a much-needed experimental research in the area of daylighting systems design and engineering. The data and knowledge base presented in this paper is currently taught to students at Oklahoma State University. Eventually, the use of the new daylighting lab will further the knowledge of the next generation of architects and architectural engineers in green design.

\section{Acknowledgement}

This material is based upon work supported by the National Science Foundation under grant No. 0310795 to Oklahoma State University. Any opinions, findings, and conclusions or recommendations expressed in this material are those of the authors and do not necessarily reflect the views of the National Science Foundation.

\section{Bibliography}

1. Khaled Mansy \& Jeff Williams, Sustainable Architecture, ... Is It a New Style?, The $22^{\text {nd }}$ International Conference on Passive and Low Energy Architecture (PLEA 2005), Beirut, Lebanon, 13-16 November, 2005.

2. Fuller Moore, Environmental Control Systems, Heating Cooling Lighting, McGraw Hill Inc., 1993. 
3. Energy Information Administration, 1995 Commercial Buildings Energy Consumption Survey, web address: www.eia.doe.gov, 2006.

4. California Public Utilities Commission, web address: www.cpuc.ca.gov, 2006.

5. Natural Resources Canada, Office of Energy Efficiency, Improving Energy Performance in Canada, Report to Parliament under the Energy Efficiency Act for Fiscal Year 2004-2005, 2005.

6. Fuller Moore, Concepts and Practice of Architectural Daylighting, Van Nostrand Reinhold, New York, 1985.

7. New Buildings Institute, Inc., Integrated Energy Systems: Productivity \& Building Science, a report prepared for California Energy Commission, 2003.

8. Andrew Marsh, Square One, web address: http://www.squ1.com/site.html, 2006.

9. Vaughn Bradshaw, Building Control Systems, $2^{\text {nd }}$ ed. , p. 284, John Wiley and Sons, 1993.

10. Khaled Mansy, A User-Friendly Procedure to Visualize the Hourly Quantitative Performance of Daylighting Systems, Solar Energy, volume 77, Elsevier, London, 2004.

11. Ibid.

12. Fuller Moore, Environmental Control Systems, Heating Cooling Lighting, p.296, McGraw Hill Inc., 1993.

13. William Lam, Sunlight as Formgiver for Architecture, p.53, Van Nostrand Reinhold, New York, 1986.

14. Khaled Mansy, A User-Friendly Procedure to Visualize the Hourly Quantitative Performance of Daylighting Systems, Solar Energy, volume 77, Elsevier, London, 2004.

15. Vaughn Bradshaw, Building Control Systems, $2^{\text {nd }}$ ed., p. 285, John Wiley and Sons, 1993.

16. Khaled Mansy, Steven O'Hara, Thomas Gedra, and Qamar Arsalan, Electronically-Controlled Artificial Sky Dome @ OSU ... in Progress, proceedings of the 2005 American Society for Engineering Education Annual Conference \& Exposition, ASEE, 2005. 